\title{
Efeitos do Trabalho Infantil sobre o Rendimento Futuro do Trabalho via Mediação da Educação
}

\author{
Mateus Mota dos Santos ${ }^{1}$ \\ ${ }^{1}$ Universidade Federal do Ceará. E-mail: matheus12_mota@hotmail.com
}

\begin{abstract}
RESUMO
Esta pesquisa analisa as consequências do trabalho infantil sobre o rendimento futuro do trabalho, transmitidas indiretamente através do nivel de escolaridade. A análise de mediação causal, desenvolvida por Imai et al. (2010a), foi aplicada aos dados da Pesquisa Nacional por Amostra de Domicílios (PNAD) de 2014. Os resultados evidenciam que as perdas salarias sofridas pelos trabalhadores brasileiros que ingressaram precocemente no mercado de trabalho não se devem exclusivamente ao fato de ter trabalho na infância, mas também são explicadas pelo prejuízo educacional sofrido devido à inserção ocupacional prematura, a qual é responsável por $80 \%$ do efeito total estimado. Os resultados também mostram que o efeito mediação ganha força nas regiões Norte, Sudeste e Nordeste do país, onde a penalização de renda, explicada pelo efeito negativo do trabalho infantil no acúmulo de capital humano, é estimada em 28,2\%, 16,8\% e 16\%, respectivamente.
\end{abstract}

\section{PALAVRAS-CHAVE}

Trabalho infantil, Educação, Análise de mediação causal

Effects of Child Labor on Future Labor Income via Education Mediation

\begin{abstract}
This research analyzes the consequences of child labor on the future income from work, transmitted indirectly through the level of education. Causal mediation analysis, developed by Imai et al. (2010a), was applied to data from the National Household Sample Survey (PNAD) of 2014. The results show that the wage losses suffered by Brazilian workers who entered the labor market early are not exclusively due to the fact of having work in childhood, but are also explained by the educational loss suffered due to premature occupational insertion, which is responsible for $80 \%$ of the total estimated effect. They also show that the mediation effect gains strength in the North, Southeast, and Northeast regions of the country, where the income penalty, explained by the negative effect of child labor on the accumulation of human capital, is estimated at $28.2 \%, 16.8 \%$ and $16 \%$, respectively.
\end{abstract}

\section{KEYWORDS}

Child labor, Education, Causal mediation analysis

\section{CLASSIFICAÇÃO JEL}

$\mathrm{J} 22, \mathrm{~J} 31$

\section{Introdução}

Por ser não apenas um problema social, mas também político e econômico (Basu, 1999), diferentes pesquisadores buscaram compreender as causas (Silva Ciríaco et al., 2019; Carrets et al., 2015; Ramalho e Mesquita, 2013; Alam et al., 2010) e consequências do trabalho infantil (Mussa et al., 2017; Houshmand et al., 2014; Emerson et al., 
2014; Bezerra et al., 2009). Embora o Brasil tenha registrado nas últimas décadas uma tendência de queda nos registros de trabalhadores infantis (Kassouf, 2015), o contingente de crianças envolvidas em atividades laborais ainda permanece preocupante.

Segundo a Organização Internacional do Trabalho (2016), cerca de 152 milhões de crianças no mundo, com idade entre 5 e 17 anos, trabalham. No Brasil, entre 1992 e 2015, 5,7 milhões de crianças e adolescentes nessa mesma faixa etária deixaram de trabalhar. Apesar do declínio, 2,7 milhões ainda se encontram em situação de trabalho infantil no país, dos quais 59\% são meninos e $41 \%$ são meninas, com maior concentração no grupo de 14 a 17 anos de idade $(83,7 \%)$. O maior contingente de crianças e adolescentes ocupados, com faixa etária de 5 a 17 anos, encontra-se no Sudeste ( 854 mil) e no Nordeste (852 mil), seguidos pelas regiões Sul (432 mil), Norte (311 mil) e Centro-Oeste (233 mil), o que torna claras as disparidades regionais existentes no país.

Dentre as principais causas do trabalho precoce, destacam-se a idade e o sexo das crianças, a pobreza, a educação dos pais, o tamanho da família, o sexo do chefe e a idade em que os pais ingressaram no mercado de trabalho (Silva Ciríaco et al., 2019; Carrets et al., 2015; Moreira et al., 2014; Kassouf, 2007). A literatura também tem revelado que filhos de advogados, médicos, e professores são menos inclinados a atividades mercantis (Basu e Tzannatos, 2003) e que a ordem de nascimento também parece relevante, já que irmãos mais velhos assumem maior probabilidade de estarem trabalhando, permitindo que os mais novos estudem (Emerson e Souza, 2008).

Além de expor crianças e adolescentes a atividades muitas vezes precárias e de baixa remuneração, o trabalho infantil pode prejudicar o desenvolvimento físico e mental (Aransiola e Justus, 2018; Nishijima et al., 2015; Fekadu et al., 2006; O’Donnell et al., 2005), a qualidade do aprendizado (Kassouf et al., 2016; Emerson et al., 2014) e a continuidade dos estudos de crianças e adolescentes (Salata, 2019), resultando, portanto, em um baixo nível educacional (Mussa, 2018; Monte, 2008; Souza e Pontili, 2008; Mattos et al., 2006). A baixa educação atingida poderá limitar as oportunidades de emprego na fase adulta (Lambon-Quayefio e Owoo, 2018; Freitas et al., 2017; Duarte e Neto, 2014; Kassouf e Santos, 2010), repercutindo negativamente no processo de desenvolvimento econômico do país. Diante disso, investigações a respeito das consequências de longo prazo desse fenômeno sobre a vida profissional e educacional do indivíduo tornam-se necessárias para uma melhor compreensão do problema, bem como de sua gravidade.

Inúmeras pesquisas, tanto a nível nacional (Freitas et al., 2017; Duarte e Neto, 2014) quanto internacional (Mussa, 2018; Lambon-Quayefio e Owoo, 2018) evidenciam que a antecipação da entrada no mercado de trabalho afeta negativamente a capacidade de ganhos na idade adulta. Entretanto, pouco se sabe a respeito da natureza causal dessa relação. Além disso, evidências sobre a parcela da penalização de renda do trabalho infantil que se deve aos prejuízos causados ao acúmulo de capital 
humano ainda permanecem inexistentes na literatura, embora muitos pesquisadores reconheçam que o baixo nível de escolaridade atingido por aqueles que desempenharam atividades econômicas na infância pode repercutir negativamente na capacidade de ganhos no futuro. Também é importante enfatizar que pouca atenção tem sido dada às disparidades regionais desse efeito na literatura brasileira, embora a questão regional seja de extrema relevância para o estudo da relação entre trabalho infantil e vida profissional futura, uma vez que esse fenômeno atinge as regiões do país de forma desigual, agindo com maior intensidade nas regiões menos desenvolvidas. Ademais, em virtude das desigualdades socioeconômicas existentes no Brasil, as perdas de longo prazo decorrentes do trabalho infantil poderão diferir significativamente entre as diferentes regiões geográficas.

Esta pesquisa busca suprir essa lacuna ao analisar as disparidades regionais do impacto do trabalho infantil sobre o rendimento futuro do trabalho, contribuindo para a literatura ao levar em consideração possiveis canais de transmissão capazes de intermediar esse efeito. Parte-se da hipótese de que a entrada antecipada no mercado laboral não afeta o salário futuro apenas de forma direta, mas principalmente indiretamente via mediação da escolaridade atingida, já que o desempenho de atividades laborais na infância aumenta os riscos de abandono escolar (Salata, 2019), podendo prejudicar o acúmulo de capital humano e, consequentemente, limitar as oportunidades ocupacionais daqueles que ingressaram mais cedo na força de trabalho, restringindo-os a ofícios que exigem baixos niveis de qualificação. Portanto, devido à importância da educação para o processo de aquisição de renda e ascensão na carreira profissional, espera-se que parte significativa do efeito total do trabalho infantil seja transmitida pela baixa escolarização daqueles que ingressaram precocemente no mercado de trabalho.

Visando atingir o objetivo proposto, utilizou-se como estratégia empírica a Análise de Mediação Causal, proposta por Imai et al. (2010a), aplicada aos dados da Pesquisa Nacional por Amostra de Domicílios (PNAD) de 2014. Esse método permite capturar a magnitude do impacto do trabalho infantil no rendimento do trabalho na idade adulta por meio de uma análise contrafactual. Diferente das alternativas tradicionais de estimação de causalidade ${ }^{1}$, essa técnica permite particionar o efeito total do trabalho infantil em dois: efeitos direto e indireto (mediação). Neste último, a inserção ocupacional precoce afetará indiretamente as recompensas salariais dos trabalhadores infantis através do nível de escolaridade atingido (variável mediadora), permitindo, assim, estimar a parcela do efeito total médio de se trabalhar na infância sobre a capacidade de geração de renda quando adulto que é explicada por seu efeito no acúmulo de capital humano, até então não investigado pela literatura.

Os resultados encontrados revelam que a inserção ocupacional prematura afeta negativamente a capacidade de geração de renda na idade adulta e que as maiores penalizações de rendimentos sofridas pelos trabalhadores que foram submetidos pre-

\footnotetext{
${ }^{1}$ Varáveis Instrumentais, Propensity Score Matching (PSM), Entropia, Diferenças em Diferenças.
} 
cocemente ao trabalho são verificadas no Centro-Oeste e no Nordeste do país. No entanto, essas perdas não se devem exclusivamente ao fato de eles terem trabalhado na infância, mas também são explicadas, principalmente, pelo prejuízo educacional sofrido devido à antecipação da entrada no mercado de trabalho. A partir da Análise de Mediação Causal, constatou-se que o impacto negativo da inserção ocupacional prematura é potencializado por seu efeito no processo de escolarização do indivíduo e que o efeito mediação causal ganha força nas regiões Norte, Sudeste e Nordeste, onde as perdas de rendimento devido ao efeito prejudicial do trabalho infantil sobre as oportunidades educacionais chegam a $28,2 \%, 16,8 \%$ e $16 \%$, respectivamente.

Portanto, os estudos que não levaram em consideração esse efeito indireto poderão superestimar o verdadeiro impacto de se trabalhar na infância no prêmio salarial futuro, uma vez que esse efeito pode ser potencializado pelo baixo nível educacional daqueles submetidos ao trabalho quando crianças.

Além desta introdução, o artigo está dividido nas seguintes seções: breve apresentação de pesquisas empíricas que investigaram as consequências a longo prazo do trabalho infantil sobre o acúmulo de capital humano e resultados do mercado de trabalho; fonte de dados e descrição das variáveis consideradas na pesquisa; discussão sobre a estratégia empírica utilizada; análise descritiva e econométrica dos dados; e considerações finais.

\section{Revisão de literatura}

Embora o trabalho infantil possa proporcionar benefícios imediatos no curto prazo, como o aumento da renda da unidade domiciliar, por exemplo, esse poderá comprometer as habilidades cognitivas (Kassouf et al., 2016; Emerson et al., 2014), a formação de capital humano (Mussa, 2018; Beegle et al., 2009; Monte, 2008; Mattos et al., 2006), além da saúde física das crianças (Kassouf e Hoffmann, 2006; Fekadu et al., 2006; O’Donnell et al., 2005), que, por sua vez, podem levar a empregos precários no futuro e, consequentemente, a baixas recompensas salarias na fase adulta da vida (Lambon-Quayefio e Owoo, 2018; Freitas et al., 2017; Duarte e Neto, 2014; Kassouf e Santos, 2010).

Investigações sobre os efeitos intertemporais do trabalho infantil sobre resultados educacionais e do mercado de trabalho têm sido cada vez mais frequentes na literatura científica. Pesquisas recentes encaram esse fenômeno como um grande obstáculo à formação de capital humano bem como à aquisição de melhores oportunidades de salários no futuro. Na Etiópia rural, Mussa et al. (2019) analisaram as consequências de longo prazo da inserção prematura no mercado de trabalho sobre os resultados educacionais de crianças acompanhadas ao longo de dezesseis anos. Seus resultados revelam que o trabalho infantil de período integral prejudica tanto a aquisição de notas quanto as transições entre os ciclos escolares. Ainda para a Etiópia, Mussa (2018) mostrou que os trabalhadores infantis de período integral geralmente acumu- 
lam menos anos de estudo e recebem, em média, 54,4\% a menos que seus pares. Com base em um método de estimativa duplamente robusta e de mínimos quadrados em três etapas, o autor também conclui que uma hora adicional de trabalho das crianças aumenta os ganhos na fase adulta da vida em 13,8\%, porém, com retornos decrescentes quando esse ocorre por mais de cinco horas diárias. Em um estudo para a região de Kagera, na Tanzânia, Burrone e Giannelli (2019), utilizando-se de modelos de probabilidade linear de efeitos fixos, observaram que a inserção precoce no mercado de trabalho está associada a empregos vulneráveis quando adulto e que os efeitos negativos no emprego futuro surgem quando as crianças trabalham acima de dez a vinte horas semanais.

Apesar de a maioria dos estudos terem identificado a entrada precoce no mercado de trabalho como prejudicial, seus efeitos sobre a capacidade de ganhos no longo prazo são fortemente duplos. Emerson e Souza (2011) argumentam que trabalhar na infância poderá prejudicar o processo de escolarização do indivíduo e, consequentemente, as chances de se conseguir melhores oportunidades laborais. Por outro lado, isso poderá gerar benefícios para o jovem trabalhador devido à acumulação de capital ocupacional proporcionado pela experiência no local de trabalho, treinamento vocacional, dentre outros. Assim, é possivel que o trabalho jovem possa proporcionar melhores resultados no mercado laboral desde que a atividade desempenhada não prejudique a continuidade dos investimentos em educação.

Para o mercado de trabalho de Gana, na África Ocidental, Lambon-Quayefio e Owoo (2018) evidenciam que a capacidade de ganhos futuros é menor para trabalhadores que ingressaram precocemente no mercado trabalhista, com diferencial de 12 a 16 pontos percentuais. Seus resultados também mostram que o desempenho de ofícios mercantis durante a infância reduz as chances de se conseguir melhores status ocupacionais quando adulto. Entretanto, o trabalho infantil contribui positivamente para a aquisição de habilidades ocupacionais, uma vez que o ingresso antecipado aumenta as chances de o indivíduo ser um profissional qualificado futuramente, com 0,213 vezes menos de probabilidade de ser trabalhador não qualificado em relação aos que entraram mais tarde na força de trabalho.

Com base em um estudo de caráter longitudinal para o Canadá, Houshmand et al. (2014) observam uma influência positiva do número de horas trabalhadas na adolescência sobre os resultados futuros no mercado de trabalho. Suas estimativas revelam que a probabilidade de ser empregado aos 17 e 19 anos é maior para estudantes que ofertaram mais horas de trabalho aos 15 anos de idade. No entanto, essa diminui quando os indivíduos se esgotam trabalhando por muitas horas, reduzindo seu tempo dedicado a atividades escolares. Os autores também evidenciam que as horas trabalhadas durante o período escolar aumentam os rendimentos dos trabalhadores aos 17 e 25 anos e que os adolescentes envolvidos em negócios da família são mais propensos a garantir emprego mais adequado nos anos seguintes.

Em contraste com a maioria dos achados empíricos que versam sobre essa temá- 
tica, Mussa et al. (2017), em um estudo para a Etiópia rural, mostraram que o trabalho infantil pode aumentar os rendimentos futuros do trabalho em torno de $10 \%$, mas que a presença de retornos decrescentes pode surgir diante de jornadas excessivas de trabalho na infância. Além disso, os autores concluem que os indivíduos que combinavam estudo e trabalho quando crianças ganham melhor do que aqueles que se dedicavam apenas a atividades escolares ou de trabalho.

Influências significativas do desempenho de atividades laborativas na infância sobre o acúmulo de capital humano e o salário também têm sido verificadas no Brasil. Ao investigar a relação entre trabalho infantil e aquisição de educação formal no Brasil, através de microdados da PNAD de 1995 e 2005, Monte (2008) observa um efeito positivo do retardamento do ingresso no mercado ocupacional sobre as características educacionais e profissionais dos indivíduos. O autor estima um aumento de 0,3 anos de estudo e uma elevação de 1,2\% no salário de trabalhadores brasileiros que adiaram sua inserção ocupacional em um ano. Ao discriminar a análise por regiões e estados da Federação, também encontra forte heterogeneidade desses efeitos, concluindo que o efeito de adiar a entrada no mercado de trabalho em um ano sobre o nível de escolaridade é mais forte nas regiões Sudeste e Nordeste do país, cujas estimativas para o ano de 2005 são 0,274 e 0,269, respectivamente. As disparidades inter-regionais dos efeitos sobre o nível de renda futuro também são constatadas e retratam uma menor influência da postergação da entrada no mercado laboral sobre o rendimento do trabalho no Sul do país $(0,9 \%)$, em relação às demais regiões, para o mesmo ano.

Em um estudo para a região Nordeste do Brasil, Mattos et al. (2006) encontram fortes evidências de um efeito negativo do trabalho infantil sobre o nível de escolaridade dos indivíduos. A partir de dados da PNAD de 2001 e da análise de regressão linear e de modelos de resposta qualitativa, os autores mostram que as pessoas que aceitaram trabalho antes dos dez anos de idade possuem, aproximadamente, dois anos a menos de estudo se comparadas com aquelas que ingressaram mais tarde na força de trabalho. Além disso, constataram que o desempenho de atividades econômicas na infância reduz a probabilidade de conclusão das etapas inicial e final do ensino fundamental em $16,58 \%$ e $20,51 \%$, respectivamente.

Especificamente para o estado do Paraná, Souza e Pontili (2008) analisaram a influência que a entrada prematura no mercado de trabalho exerce sobre a capacidade de geração de renda e de acúmulo de capital humano de trabalhadores com idade entre 18 e 60 anos. Utilizando-se de dados da PNAD de 2005, esses constataram que o ingresso ocupacional prematuro reflete em menores anos de estudo e em baixos níveis de salário e que a maior penalização incide sobre aqueles que desempenharam atividades laborais antes dos nove anos de idade, cujas perdas são estimadas em $15,9 \%$ e $26,1 \%$, para o meio urbano e rural, respectivamente, se comparados com seus colegas que começaram a trabalhar após completar 18 anos.

Kassouf e Santos (2010) observaram, através de microdados da PNAD de 2007, que, mesmo após o controle de características pessoais e de trabalho dos indivíduos, 
a inserção prematura afeta negativamente os rendimentos futuros e que a magnitude desse efeito difere entre gênero e regiões do Brasil. A nível agregado, os autores estimam uma redução de $6,4 \%$ no salário daqueles que trabalharam quando criança. Ao discriminar por sexo e região, os autores observam um menor prejuízo de se trabalhar na infância para homens do Nordeste $(3,2 \%)$ e maior penalização para as mulheres que vivem no Sul do país $(13,7 \%)$.

A existência de uma idade mínima em que a influência negativa da inserção antecipada no mercado de trabalho sobre o salário e as chances de conclusão do ensino médio torna-se positiva tem sido evidenciada por Paiva (2013), o qual constatou que o efeito negativo do trabalho infantil sobre o salário, entre 20 e 29 anos, torna-se positivo quando a entrada no mercado de trabalho ocorre a partir do 15 anos de idade e que a probabilidade de concluir o ensino médio até os 21 anos é reduzida quando essa inserção se dá abaixo desse nível.

Duarte e Neto (2014), com base em informações da PNAD de 2009 e uso de regressão quantílica, encontram uma influência negativa do trabalho precoce sobre o rendimento futuro dos trabalhadores em todos os quantis de renda, agindo com maior intensidade na região Nordeste quando comparada ao Sul do país, cuja redução salarial no quantil mais baixo da distribuição de renda chega a $26 \%$, enquanto na região Sul é de apenas 22\%, aproximadamente. Além disso, as estimativas para os últimos quantis da distribuição de rendimentos para a região Sul não foram estatisticamente significantes, sugerindo não haver diferenças significativas de renda entre os que trabalharam ou não quando criança.

Em um estudo mais recente para o Brasil, Freitas et al. (2017) também encontram resultados que sustentam essa relação. Utilizando-se de informações provenientes da PNAD de 2008 e com o auxílio de modelos de momentos generalizados, além de regressão quantílica, os autores constataram que o salário dos indivíduos que trabalharam quando criança são menores do que os de seus pares que não trabalharam e que tal influência varia segundo o nível de renda do indivíduo, sendo maior para estratos mais elevados (quantil 0,75). Eles estimam uma redução de 2,27\% no salário daqueles trabalhadores que ingressaram no mercado de trabalho com idade entre 10 e 14 anos.

Diante do exposto, nota-se que a atividade laboral precoce assume múltiplas consequências de longo prazo, como baixos níveis de escolaridade e de rendimentos auferidos na fase adulta da vida. Uma vez que o trabalho infantil reduz as oportunidades educacionais, é possivel que o impacto da entrada antecipada no mercado de trabalho sobre o salário seja potencializado pelo baixo acúmulo de capital humano daqueles que foram trabalhadores infantis. Dessa forma, espera-se que uma parcela significativa da influência do trabalho infantil no salário dar-se-á de forma indireta, via status educacional. 


\section{Metodologia}

\subsection{Base de dados e descrição das variáveis}

Os dados utilizados nesta pesquisa foram extraídos da Pesquisa Nacional por Amostra de Domicílios (PNAD) de 2014, do Instituto Brasileiro de Geografia e Estatística (IBGE). Para esse ano, a PNAD disponibilizou um Suplemento de Mobilidade SócioOcupacional aplicado a uma parcela da amostra original da pesquisa, com a finalidade de captar características relativas à mobilidade sócio-ocupacional dos entrevistados. Em razão da disponibilidade e da riqueza de informações retrospectivas presentes nessa subamostra, decidiu-se trabalhar especificamente com esse suplemento. A grande vantagem de utilizar esse suplemento está na possibilidade de identificar a educação do pai e da mãe dos indivíduos, a qual é vista como um forte determinante do status educacional dos filhos (Junior et al., 2013; Reis e Ramos, 2011), independente de esses ainda morarem no mesmo domicílio que seus pais. Outra vantagem é que essas informações são referentes à época em que os entrevistados ainda tinham 15 anos, ou seja, antes da idade mínima requerida para o desempenho de atividades econômicas. Assim, foram considerados nessa pesquisa apenas os indivíduos com idade entre 20 e 60 anos, inclusive, que estavam trabalhando na semana de referência e que foram alvos desse suplemento de mobilidade sócio-ocupacional, resultando em uma amostral final de 21.723 indivíduos.

Como a decisão de participação no mercado de trabalho não é exógena, pois depende do processo de comparação do salário de reserva ${ }^{2}$ com aquele ofertado pelo mercado, considerar na análise apenas indivíduos que trabalham, bem como somente aqueles que foram selecionados para responder o questionário referente ao suplemento sobre mobilidade sócio-ocupacional da PNAD poderá resultar em problemas de viés de seleção amostral, visto que, nesse caso, a amostra não foi selecionada de forma aleatória. Para corrigir esse problema, esta pesquisa utilizará o procedimento de Heckman (1979) em dois estágios. No primeiro estágio, estimou-se uma equação de participação por meio de um modelo de regressão probit, com o uso de uma amostra composta por pessoas com idade entre 20 e 60 anos que foram selecionadas ou não para responder o questionário referente ao suplemento de mobilidade sócioocupacional, estando esses empregados ou não na semana de referência, a partir da qual se obteve a razão inversa de Mills (IMR). Para corrigir o viés de seleção amostral, estimou-se no segundo estágio a equação de rendimentos incluindo a razão inversa de Mills nas covariadas do modelo de mediação.

As variáveis consideradas na análise são descritas no Guadro 1. A variável de resultado potencial diz respeito ao logaritmo do salário mensal por hora trabalhada no trabalho principal da semana de referência, enquanto a de mediação corresponde

\footnotetext{
${ }^{2}$ Entende-se por salário de reserva o salário a partir do qual o indivíduo decide aceitar uma oferta de emprego. Seja w o salário oferecido pelo emprego e r o salário de reserva do trabalhador. Quando $\mathrm{w}<\mathrm{r}$ esse rejeita a oferta de trabalho; e aceita quando w $>$ r. O trabalhador estará indiferente entre aceitar ou não à oferta de emprego quando w=r.
} 
ao nível de escolarização atingido pelo indivíduo. Uma vez que a Constituição Federal de 1988 (art. $7^{\circ}$, XXXIII) só permite o trabalho a partir dos 16 anos de idade, exceto quando na condição de aprendiz, cuja idade mínima permitida é de 14 anos, serão considerados nesta pesquisa como trabalhadores infantis apenas aqueles que exerceram atividade mercantil antes dos 16 anos de idade. Diante disso, a variável de tratamento, Trabalho Infantil, construída a partir de informações retrospectivas presentes no questionário da PNAD de 2014, assumirá valor um caso o indivíduo tenha começado a trabalhar antes dos 16 anos de idade e zero se entrou mais tarde no mercado de trabalho.

Quadro 1. Descrição das variáveis

\begin{tabular}{|l|l|}
\hline Variáveis & Descrição \\
\hline Resultado & $\begin{array}{l}\text { Logaritmo natural do salário mensal por hora trabalhada } \\
\text { no trabalho principal }\end{array}$ \\
\hline LnSalário & \multicolumn{2}{|l|}{$\begin{array}{l}1=\text { se começou a trabalhar com menos de 16 anos de } \\
\text { Tratamento }\end{array}$} \\
\hline TrabalhoInfantil $0=$ caso contrário
\end{tabular}

Fonte: Elaboração própria.

Nota: * informações retrospectivas referentes ao período em que os entrevistados ainda eram adolescentes, com 15 anos, ou seja, antes da idade mínima requerida para o trabalho. 


\subsection{Estratégia empirica}

\subsubsection{Efeitos causais do trabalho infantil via mediação da educação}

Nos problemas de estimativas causais, a identificação da direção do efeito de uma variável de tratamento em outra de resultado, longe da influência de outros fatores capazes de contaminar essa relação, consiste no objetivo principal. Todavia, os métodos tradicionais, como Propensity Score Matching (PSM), Diferença em Diferenças, Entropia, dentre outros, não fornecem informações adicionais a respeito da construção desses efeitos, isto é, do caminho percorrido pela variável de tratamento até que essa afete a de resultado. A técnica de Análise de Mediação Causal busca suprir esta lacuna ao estimar a parcela do efeito do tratamento $\mathrm{T}$ na variável de resultado $\mathrm{Y}$ que é transmitido por uma variável intermediária M, responsável por ligar a influência do tratamento sobre o resultado de interesse.

O objetivo desta pesquisa consiste em identificar o efeito do trabalho infantil $(T)$ sobre o rendimento do trabalho na fase adulta da vida $(Y)$ que é explicado por seu efeito na educação atingida pelo indivíduo $(M)$. Para isso, seguimos a abordagem de mediação causal descrita em Imai et al. (2010a) e Imai et al. (2011), a qual permite decompor o efeito total da inserção ocupacional prematura em duas parcelas: efeito indireto (mediação), transmitido pelo nível de escolaridade (variável mediadora), e efeito direto, o qual inclui todos os outros mecanismos potenciais através dos quais o desempenho de atividades mercantis na infância pode afetar a capacidade de ganhos na idade adulta.

O método de Análise de Mediação Causal foi inicialmente formulado e aplicado nas ciências sociais dentro da estrutura de modelos de equações lineares por haver dificuldades de sua expansão para o caso não linear. Além disso, as estimativas obtidas por meio de modelos estruturais lineares ainda se mostravam problemáticas em virtude da impossibilidade de especificação de uma suposição de identificação chave, devido à interdependência dos resultados a um modelo específico. Com o intuito de superar essa limitação, Imai et al. (2010b) formularam uma nova abordagem, dentro da estrutura de análise contrafactual, generalizada para o quadro de modelos lineares e não lineares, paramétricos e não paramétricos, além de permitir a utilização de mediadores contínuos e discretos.

Para definir os efeitos indiretos no âmbito da estrutura contrafactual de resultados potenciais, deixando $M_{i}(t)$ denotar o valor potencial da variável mediadora para o indivíduo $i$ na situação de tratamento $T_{i}=t$, e $Y_{i}(t, m)$ o resultado potencial que resultaria se o valor da variável de tratamento e de mediação fossem, respectivamente, $t$ e $m$. Então, as variáveis observadas podem ser escritas como $M_{i}\left(T_{i}\right)$ e $Y_{i}\left(T_{i}, M_{i}\left(T_{i}\right)\right)$. Observa-se que, na Análise de Mediação Causal, o resultado observado depende tanto do status de tratamento quanto da variável mediadora sob o nível de tratamento observado. Assim, usando a estrutura de resultados potenciais, o efeito mediação do trabalho infantil para o indivíduo $i$ sob o status de tratamento $t$, pode ser escrito como 


$$
\varphi_{i}(t) \equiv Y_{i}\left(t, M_{i}(1)\right)-Y_{i}\left(t, M_{i}(0)\right)
$$

para cada estado de tratamento $t=0,1$. Essa quantidade captura a mudança no salário do indivíduo $i$ correspondente a uma mudança em sua educação (mediador), da que seria observada sob o status de controle (não trabalhou na infância), ou seja, $M_{i}(0)$, para a que seria obtida sob a condição de tratamento (trabalhou na infância), $M_{i}(1)$, enquanto o status de tratamento é mantido constante em $t$. Ao fixar o tratamento e alterar apenas o mediador, os demais mecanismos através dos quais a variável de tratamento afeta a de resultado são eliminados e o mecanismo hipotético de interesse é isolado (Imai et al., 2011). Desse resultado, pode-se observar também que, sob o status de tratamento $t$, o resultado contrafactual $Y_{i}\left(t, M_{i}(1-t)\right)$ nunca é observado. Isso ressalta a dificuldade de identificar mecanismos causais.

Definindo $\varphi_{i}(t)=\varphi_{i}(1)$, tem-se que $Y_{i}\left(1, M_{i}(1)\right)$ representa o salário auferido pelo indivíduo $i$ que ingressou precocemente no mercado de trabalho; e o resultado $Y_{i}\left(1, M_{i}(0)\right)$ diz respeito ao salário que ele receberia se tivesse atingido o mesmo nível educacional que seria obtido no cenário contrafactual. Percebe-se, portanto, que no processo de estimação do efeito indireto o tratamento permanece fixo enquanto o mediador segue variando. Isso permite responder à seguinte pergunta: quanto de salário o indivíduo que trabalhou na infância receberia a mais (ou a menos) se tivesse atingido o mesmo status de educação que seria obtido caso tivesse postergado sua inserção no mercado de trabalho?

Por outro lado, no efeito direto, a variável mediadora é mantida constante enquanto o status de tratamento varia, permitindo, dessa forma, capturar a parcela do efeito total do trabalho infantil sobre os salários que não é transmitida pelo grau de escolarização do indivíduo:

$$
\delta_{i}(t) \equiv Y_{i}\left(1, M_{i}(t)\right)-Y_{i}\left(0, M_{i}(t)\right)
$$

para cada unidade $i$ e status de tratamento $t=0,1$. Desse modo, $\delta_{i}(1)$ representa a diferença entre $Y_{i}\left(1, M_{i}(1)\right)$, o salário recebido pelo indivíduo $i$ que ingressou precocemente no mercado de trabalho, e $Y_{i}\left(0, M_{i}(1)\right)$ correspondente ao salário contrafactual que seria obtido pelo mesmo indivíduo caso não tivesse trabalho enquanto criança, mantendo seu status educacional constante.

A soma dos efeitos direto e indireto produz o efeito total do indivíduo $i$ ter sido trabalhador infantil sobre a capacidade de ganhos na idade adulta, dado pela terceira equação abaixo. Assim, uma análise de mediação causal representa uma decomposição do efeito total nos efeitos direto e indireto (mediação). 


$$
\tau_{i}(t) \equiv Y_{i}\left(1, M_{i}(1)\right)-Y_{i}\left(0, M_{i}(0)\right)=\frac{1}{2} \sum_{t=0}^{1}\left\{\varphi_{i}(t)+\delta_{i}(t)\right\}
$$

Como inexistem informações a respeito dos resultados do mercado de trabalho que seriam observados para o indivíduo $i$ que trabalhou na infância caso este não tivesse ingressado precocemente no mercado de trabalho, a estimativa individual do efeito do trabalho infantil para a unidade $i$ torna-se inviável, sendo possível estimar apenas o efeito médio sobre a população em estudo. Diante disso, esta pesquisa se concentra nos efeitos médios de mediação e nos efeitos diretos médios, formalmente definidos como $\bar{\varphi}_{i}(t) \equiv E\left[Y_{i}\left(t, M_{i}(1)\right)-Y_{i}\left(t, M_{i}(0)\right)\right]$ e $\bar{\delta}_{i}(t) \equiv E\left[Y_{i}\left(1, M_{i}(t)\right)-Y_{i}\left(0, M_{i}(t)\right)\right]$, respectivamente. A soma dessas quantidades produz o efeito total médio, $\bar{\tau}_{i}(t) \equiv$ $E\left[Y_{i}\left(1, M_{i}(1)\right)-Y_{i}\left(0, M_{i}(0)\right)\right]=\frac{1}{2} \sum_{t=0}^{1}\left\{\bar{\varphi}_{i}(t)+\bar{\delta}_{i}(t)\right\}$.

Para quantificar esses efeitos, precisa-se primeiramente estimar os resultados e mediadores potenciais. Para isso, usamos os seguintes modelos de regressão linear para modelar a variável de mediação $M_{i}$ (nível de escolarização obtido pelo indivíduo) e a de resultado $Y_{i}$ (logaritmo natural do salário mensal por hora trabalhada no trabalho principal):

$$
\begin{gathered}
M_{i}=\alpha_{1}+\beta_{1} T_{i}+\xi^{\prime} X_{i}+\epsilon_{i 1} \\
Y_{i}=\alpha_{2}+\beta_{2} T_{i}+\gamma M_{i}+\xi^{\prime} X_{i}+\epsilon_{i 2}
\end{gathered}
$$

O vetor $X_{i}$ é formado pelo conjunto de covariáveis de pré-tratamento; $\epsilon_{i 1}$ e $\epsilon_{i 2}$ representam o termo de erro da equação de mediação e de resultado, respectivamente.

Diante do exposto, seguindo Bellani e Bia (2019), a estimativa do Efeito Médio de Mediação Causal (ACME) pode ser obtida pela diferença média nos resultados previstos ao longo dos níveis de escolarização atingidos, para o caso de ter ou não trabalhado na infância:

$$
\widehat{\bar{\varphi}}(t) \equiv \frac{1}{n} \sum_{i=1}^{n}\left\{\bar{Y}_{i}\left(t, \bar{M}_{i}(1)\right)-\bar{Y}_{i}\left(t, \bar{M}_{i}(0)\right)\right\}
$$

Da mesma forma, a estimativa do Efeito Médio Direto (EMD) pode ser obtida pela diferença média dos salários previstos para os diferentes estados de tratamento:

$$
\widehat{\bar{\delta}}(t) \equiv \frac{1}{n} \sum_{i=1}^{n}\left\{\bar{Y}_{i}\left(1, \bar{M}_{i}(t)\right)-\bar{Y}_{i}\left(0, \bar{M}_{i}(t)\right)\right\}
$$




\subsubsection{Ignorabilidade sequencial}

A Ignorabilidade Sequencial (IS) é a principal premissa que permite a realização de inferências válidas dos efeitos de mediação causal (Imai et al., 2011). Seja $X_{i}$ o vetor de variáveis pré-tratamento para a unidade $i$ e $\mathcal{X}$ o suporte da distribuição de características de pré-tratamento, então, a hipótese de IS pode ser apresentada da seguinte forma:

$$
\begin{aligned}
& \left\{Y_{i}\left(t^{\prime}, m\right), M_{i}(t)\right\} \perp T_{i} \mid, X_{i}=x_{i}, \\
& Y_{i}\left(t^{\prime}, m\right) \perp M_{i}(t) \mid T_{i}=t, X_{i}=x_{i},
\end{aligned}
$$

em que $0<\operatorname{Pr}\left(T_{i}=t \mid X_{i}=x\right)$ e $0<p\left(M_{i}(t)=m \mid T_{i}=t, X_{i}=x\right)$ dado $t=0,1$, e todo $x \in \mathcal{X}$ e $m \in \mathcal{M}$.

Essa hipótese recebe esse nome porque as duas suposições de ignorabilidade são produzidas sequencialmente. Na primeira premissa, assume-se que, condicional às covariáveis de pré-tratamento, a atribuição ao tratamento (ter sido trabalhador infantil) é estatisticamente independente do resultado potencial (rendimento do trabalho na idade adulta) e do mediador (escolaridade). Neste estudo, os indivíduos não foram distribuídos aleatoriamente nos grupos de tratamento (composto pelos que ingressaram precocemente no mercado de trabalho) e de controle (formado por aqueles que não foram submetidos a atividades mercantis antes da idade mínima requerida para o trabalho). Isso significa que podem existir fatores não observados que motivaram, de certa forma, a decisão de ingressar precocemente no mercado de trabalho, mesmo após o controle de um conjunto de características observáveis disponíveis no banco de dados aqui considerado. Assim, os indivíduos podem ter se autosselecionado para o grupo de tratamento.

A segunda premissa diz que, condicional ao tratamento e às covariáveis pré-tratamento, o resultado potencial é estatisticamente independente do mediador. Ao contrário da ignorabilidade da atribuição ao tratamento, a ignorabilidade da variável de mediação pode não ser satisfeita mesmo em experimentos aleatórios. Nesta pesquisa, é possível que essa hipótese não seja atendida, pois, devido ao longo período de tempo entre a exposição ao tratamento (trabalhar enquanto criança) e o nivel educacional atingido, podem existir fatores de confusão não observados que poderiam motivar o processo de aquisição tanto de renda quanto de escolaridade, confundindo a relação entre o resultado e o mediador, mesmo após o controle de um rico conjunto de informações disponível na base de dados aqui considerada. Por exemplo, as habilidades cognitivas e não cognitivas do indivíduo, características não controladas na análise, poderiam aumentar suas chances de adquirir maiores niveis de instrução e, consequentemente, melhores oportunidades de trabalho. 


\subsubsection{Análise de sensibilidade}

Tendo em vista que a hipótese de IS não pode ser contestada a partir de informações observacionais (Keele et al., 2015), Imai et al. (2010a) e Imai et al. (2010b) desenvolveram testes de sensibilidade capazes de avaliar a robustez dos resultados a existência de possiveis fatores de confusão não observados ao quantificar o desvio máximo permitido da suposição de identificação chave para que as conclusões originais da pesquisa sejam mantidas. Na análise de sensibilidade proposta, a violação hipotética da hipótese de IS baseia-se na correlação entre os termos de erro das Equações (4) e (5), $\rho \equiv \operatorname{Corr}\left(\epsilon_{i 1}, \epsilon_{i 2}\right)$. Se a suposição de IS for mantida, todos os fatores de confusão de pré-tratamento relevantes foram condicionados e, portanto, o parâmetro de sensibilidade $\rho$ será zero. Por outro lado, valores de $\rho$ diferentes de zero implicam desvios da suposição de ignorabilidade e, consequentemente, estimativas viesadas do efeito mediação. Por exemplo, se as habilidades cognitivas e não cognitivas dos sujeitos os tornam mais propensos a demandarem maiores niveis de escolaridade e a adquirirem melhores rendimentos, $\rho$ será positivo. Assim, a ideia central do teste está em identificar os valores hipotéticos de $\rho$ para os quais o efeito mediação seja zero.

Como a interpretação direta do parâmetro de sensibilidade é bastante difícil, os autores propuseram uma abordagem alternativa baseada na seguinte decomposição dos termos de erro das Equações (4) e (5): $\epsilon_{i j}=\lambda_{j} U_{i}+\epsilon_{i j}^{\prime}$, para $j=1,2$, em que $U_{i}$ é um fator de confusão de pré-tratamento não observado que influencia o mediador e o resultado, e $\lambda_{j}$ é um coeficiente desconhecido de cada equação. Eles mostram que a influência desse fator de confusão pode ser expressa em função dos seguintes coeficientes de determinação: $R_{M}^{2 *}=1-\operatorname{Var}\left(\epsilon_{i 1}^{\prime}\right) / \operatorname{Var}\left(\epsilon_{i 1}\right)$ e $R_{Y}^{2 *}=1-\operatorname{Var}\left(\epsilon_{i 2}^{\prime}\right) / \operatorname{Var}\left(\epsilon_{i 2}\right)$, que representam, respectivamente, a proporção da variação não explicada no mediador e no resultado que é explicada pelo fator de confusão não observado. Outra interpretação alternativa é baseada na proporção da variância original que é explicada pelo fator de confusão omitido no modelo de mediação e no de resultado: $\widetilde{R}_{M}^{2}=\left(\operatorname{Var}\left(\epsilon_{i 1}\right)-\operatorname{Var}\left(\epsilon_{i 1}^{\prime}\right)\right) / \operatorname{Var}\left(M_{i}\right)$ e $\widetilde{R}_{Y}^{2}=\left(\operatorname{Var}\left(\epsilon_{i 2}\right)-\operatorname{Var}\left(\epsilon_{i 2}^{\prime}\right)\right) / \operatorname{Var}\left(Y_{i}\right)$. Assim, de acordo com (Imai et al., 2010b), o parâmetro de sensibilidade $\rho$ pode ser escrito como

$$
\rho=\operatorname{sgn}\left(\lambda_{1} \lambda_{2}\right) R_{M}^{2 *} R_{Y}^{2 *}=\frac{\operatorname{sgn}\left(\lambda_{1} \lambda_{2}\right) \widetilde{R}_{M}^{2} \widetilde{R}_{Y}^{2}}{\sqrt{\left(1-R_{M}^{2}\right)\left(1-R_{Y}^{2}\right)}}
$$

onde $\operatorname{sgn}\left(\lambda_{1} \lambda_{2}\right)$ representa o sinal do produto dos coeficientes não observados $\lambda_{1}$ e $\lambda_{2}$, e $R_{M}^{2}$ e $R_{Y}^{2}$ medem, respectivamente, o coeficiente de determinação das Equações (4) e (5). Assim, pode-se examinar a sensibilidade das estimativas à violação da hipótese de IS variando os valores de $R_{M}^{2 *} R_{Y}^{2 *}$ ou $\widetilde{R}_{M}^{2} \widetilde{R}_{Y}^{2}$ para os casos em que o fator de confusão omitido afeta a variável de resultado e de mediação na mesma direção, $\operatorname{sgn}\left(\lambda_{1} \lambda_{2}\right)>0$, ou em direções contrárias, $\operatorname{sgn}\left(\lambda_{1} \lambda_{2}\right)<0$. 


\section{Resultados}

\subsection{Análise descritiva dos dados}

Na Tabela 1, são apresentadas as estatísticas descritivas para as variáveis-chave da amostra para o Brasil e as regiões geográficas, condicionadas ao fato de o indivíduo ter trabalhado na infância ou não. Os reflexos do trabalho infantil sobre a capacidade de geração de renda e de aquisição de educação na fase adulta da vida são claros. Além de receberem menores salários, os trabalhadores infantis também atingem menores graus de instrução quando comparados aos que ingressam mais tarde no mercado de trabalho. No Brasil, a renda média dos indivíduos que começaram a trabalhar a partir dos 16 anos de idade supera a renda dos que ingressaram mais cedo em $18,8 \%$. Ademais, a escolaridade média daqueles supera a que é registrada por estes em aproximadamente três anos.

As estatísticas descritivas para as grandes regiões do país revelam que a desigualdade média de renda e de escolarização, a favor das pessoas que não ingressaram precocemente no mercado de trabalho, é mais expressiva no Nordeste, sugerindo, portanto, que a atividade laboral precoce parece mais prejudicial ao avanço educacional e ao processo de aquisição de renda nessa região do que nas demais. Conforme reportado na Tabela 1, na região Nordeste, a escolaridade média das pessoas que adiaram sua entrada no mercado de trabalho supera a das que foram submetidas precocemente ao trabalho em quase quatro anos, e o diferencial de renda chega a $28 \%$. No Sul do país, por outro lado, os danos causados pelo trabalho infantil parecem bem menores, uma vez que os diferenciais de rendimentos $(9,1 \%)$ e de escolaridade $(2,5$ anos de estudo) são significativamente menores.

Para uma melhor compreensão de como os trabalhadores, submetidos ou não à atividade laboral prematura, estão distribuídos nos diferentes estratos de escolaridade, um resumo mais detalhado de suas características educacionais é apresentado na Figura 1. A parte cinza de cada gráfico corresponde à parcela de trabalhadores que entraram no mercado de trabalho a partir dos 16 anos de idade, enquanto a proporção mais escura diz respeito àqueles que desempenharam atividades econômicas antes dos 16 anos.

Observa-se, de imediato, que a interrupção do processo de acumulação de capital humano ocorre com maior frequência entre os trabalhadores que exerceram atividade laborativa na infância. Aproximadamente 83,9\% e 75,7\% dos trabalhadores brasileiros sem instrução e com ensino fundamental incompleto, respectivamente, trabalharam quando criança, contra um total de apenas $16,1 \%$ e $24,3 \%$ daqueles que entraram mais tarde na força de trabalho. Em relação ao total de pessoas com ensino superior, apenas $26,6 \%$ trabalharam na infância e 73,4\% não foram submetidas a nenhuma forma de atividade mercantil antes dos 16 anos de idade.

Em relação às grandes regiões geográficas, constata-se que trabalhar antes dos 
Tabela 1. Estatísticas descritivas

\begin{tabular}{l|c|c|c|c}
\hline \hline \multicolumn{5}{c}{ Brasil } \\
\hline \multirow{2}{*}{ Variáveis } & Trabalhou na Infância & Não Trabalhou na Infância \\
\cline { 2 - 5 } & Média & Desvio Padrão & Média & Desvio Padrão \\
\hline LnSalário & 2,2902 & 2,7604 & 2,7201 & 3,0236 \\
Escolaridade & 8,0194 & 4,3029 & 11,1465 & 3,5176 \\
N $^{\circ}$ Observações & 11.322 & 10.401 & \\
\hline \multicolumn{5}{c}{ Norte } \\
\hline \multicolumn{1}{c}{ Variáveis } & Trabalhou na Infância & Não Trabalhou na Infância \\
\cline { 2 - 5 } & Média & Desvio Padrão & Média & Desvio Padrão \\
\hline LnSalário & 2,0732 & 2,5274 & 2,6202 & 3,1147 \\
Escolaridade & 7,3347 & 4,369 & 10,6394 & 3,5864 \\
No Observações & 1.422 & \multicolumn{3}{c}{1.198} \\
\hline
\end{tabular}

\section{Nordeste}

\begin{tabular}{l|cc|c|c}
\hline \multirow{2}{*}{ Variáveis } & \multicolumn{2}{|c|}{ Trabalhou na Infância } & \multicolumn{2}{c}{ Não Trabalhou na Infância } \\
\cline { 2 - 5 } & Média & Desvio Padrão & Média & Desvio Padrão \\
\hline LnSalário & 1,7922 & 2,4398 & 2,289 & 2,4905 \\
Escolaridade & 6,7397 & 4,46 & 10,6831 & 3,6514 \\
N $^{\text {O Observações }}$ & 2.893 & & 2.739 & \\
\hline
\end{tabular}

\begin{tabular}{|c|c|c|c|c|}
\hline \multicolumn{5}{|c|}{ Sudeste } \\
\hline \multirow[b]{2}{*}{ Variáveis } & \multicolumn{2}{|c|}{ Trabalhou na Infância } & \multicolumn{2}{|c|}{ Não Trabalhou na Infância } \\
\hline & Média & Desvio Padrão & Média & Desvio Padrão \\
\hline LnSalário & 2,6823 & 3,4133 & 3,0786 & 3,6551 \\
\hline Escolaridade & 8,7089 & 4,0582 & 11,4614 & 3,3791 \\
\hline $\mathrm{N}^{\circ}$ Observações & 3.484 & & 3.472 & \\
\hline
\end{tabular}

\begin{tabular}{|c|c|c|c|c|}
\hline \multicolumn{5}{|c|}{ Sul } \\
\hline \multirow[b]{2}{*}{ Variáveis } & \multicolumn{2}{|c|}{ Trabalhou na Infância } & \multicolumn{2}{|c|}{ Não Trabalhou na Infância } \\
\hline & Média & Desvio Padrão & Média & Desvio Padrão \\
\hline LnSalário & 2,4799 & 2,5244 & 2,7056 & 2,491 \\
\hline Escolaridade & 8,8535 & 3,9812 & 11,3732 & 3,38 \\
\hline $\mathrm{N}^{\mathrm{o}}$ Observações & 2.233 & & 1.897 & \\
\hline \multicolumn{5}{|c|}{ Centro-Oeste } \\
\hline \multirow{2}{*}{ Variáveis } & \multicolumn{2}{|c|}{ Trabalhou na Infância } & \multicolumn{2}{|c|}{ Não Trabalhou na Infância } \\
\hline & Média & Desvio Padrão & Média & Desvio Padrão \\
\hline LnSalário & 2,2591 & 1,7093 & 2,7956 & 2,5961 \\
\hline Escolaridade & 8,3379 & 4,2673 & 11,4694 & 3,5817 \\
\hline $\mathrm{N}^{\mathrm{o}}$ Observações & 1.290 & & 1.095 & \\
\hline
\end{tabular}

Fonte: Elaboração própria a partir dos dados da PNAD de 2014. 
Figura 1. Distribuição dos trabalhadores infantis por nível de escolaridade
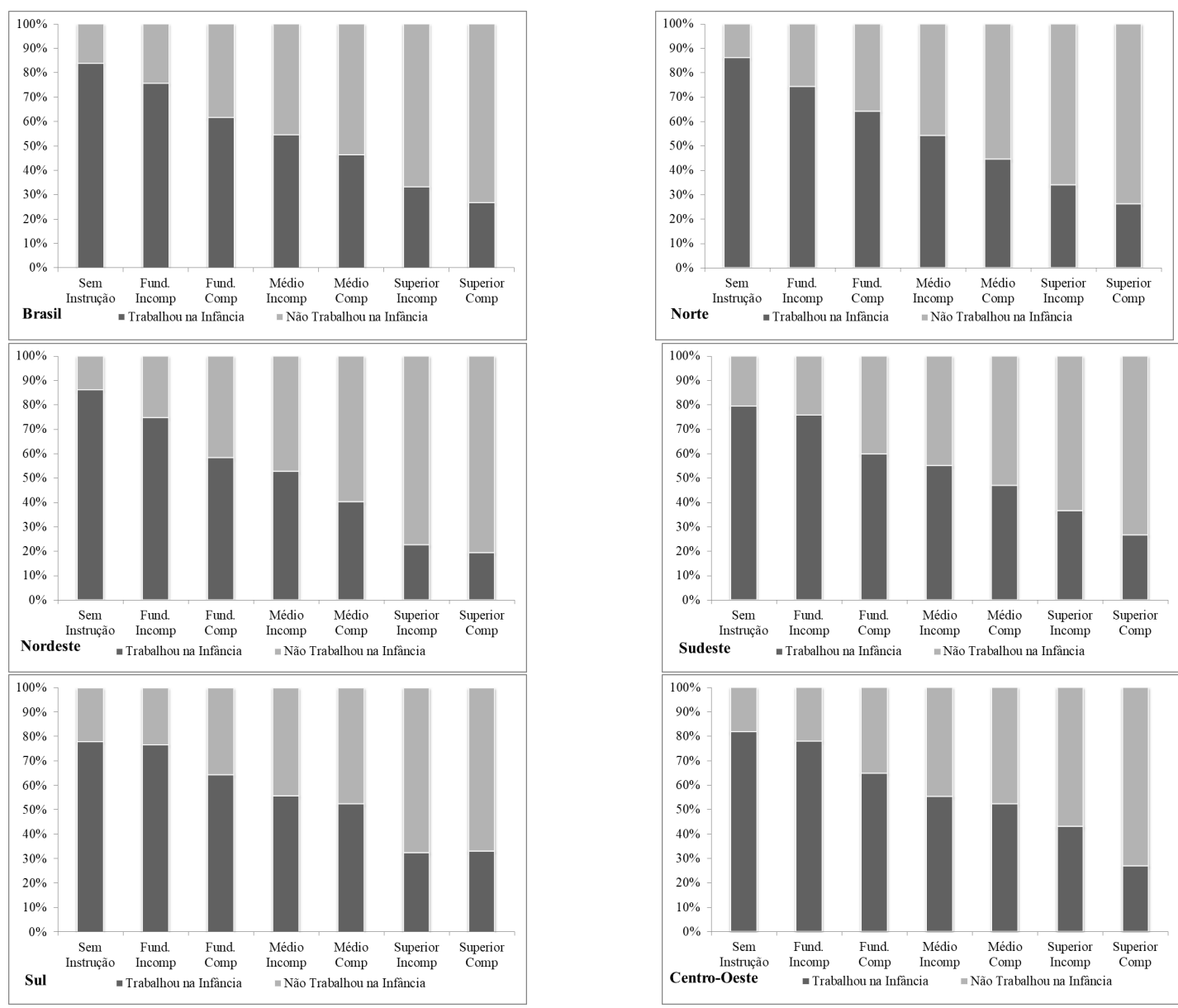

Fonte: Elaboração própria a partir dos dados da PNAD de 2014.

16 anos parece mais prejudicial ao acúmulo de capital humano no Nordeste, onde aproximadamente $86,1 \%$ e $74,7 \%$ da força de trabalho sem instrução e com ensino fundamental incompleto, respectivamente, ingressou prematuramente no mercado laboral, enquanto apenas 19,3\% daqueles com ensino superior completo começaram a trabalhar antes dos 16 anos. Nota-se também que, entre as regiões brasileiras, o Sul é a que apresenta o menor contingente de indivíduos sem instrução que trabalharam quando criança (78\%) e a que possui o maior percentual de trabalhadores com ensino superior completo que foram trabalhadores infantis (33\%).

Diante do exposto, é possivel inferir que o nível de capital humano acumulado ao longo do tempo é um potencial mediador do efeito do trabalho infantil sobre os rendimentos na fase adulta da vida, já que menores niveis de escolaridade proporcionam ao indivíduo oportunidades limitadas de trabalho, restringindo-o a atividades que requerem mão de obra menos qualificada e de baixa remuneração. Assim, o efeito do trabalho infantil sobre a educação poderá potencializar seu efeito sobre os níveis de salário adquiridos na fase adulta. Portanto, ressalta-se mais uma vez que os estudos que não levaram em conta esse efeito indireto, transmitido pelo status de educação, poderão superestimar a verdadeira influência do trabalho precoce no processo de ge- 
ração de renda do trabalhador adulto.

\subsection{Resultados econométricos}

Os resultados do efeito total e dos efeitos direto e indireto (mediação) do trabalho infantil sobre o rendimento futuro do trabalho, levando em consideração os pesos amostrais da PNAD com a intensão de fornecer estimativas próximas aos valores populacionais, são reportados na Tabela 2. A fim de verificar a sensibilidade desses resultados ao viés de seletividade amostral, decorrente da seleção não aleatória da amostra, as estimativas obtidas antes e após a correção desse problema por meio do procedimento de Heckman (1979) em duas etapas são apresentadas nessa tabela.

Evidências da existência de uma penalização de renda devido à inserção ocupacional prematura no mercado de trabalho são constatadas. O desempenho de atividades mercantis antes da idade mínima para o trabalho reduz as possibilidades de rendimentos na fase adulta da vida no Brasil, independente da região geográfica. As estimativas não corrigidas para o problema de seletividade amostral apontam para um efeito total negativo e estatisticamente significante ao nível de significância de 5\% em todas as macrorregiões do país. No entanto, a consistência desses resultados à correção do viés de seleção é verificada apenas nas regiões Nordeste e Centro-Oeste, onde as estimativas do efeito total continuaram significantes.

Os resultados também indicam que uma parcela significativa dessa penalização de renda se deve ao efeito prejudicial do trabalho infantil sobre a continuidade do investimento em educação, visto que o Efeito Médio de Mediação Causal (ACME) via educação é negativo e estatisticamente significante a menos de $1 \%$ de significância, mesmo depois da correção do viés de seleção amostral. Um efeito indireto (mediação) negativo se justifica pelo fato de a atividade laboral precoce afetar negativamente o processo de escolarização do indivíduo (Monte, 2008; Mattos et al., 2006), reduzindo suas possibilidades de rendimento no mercado de trabalho devido à baixa educação adquirida.

As estimativas para o Brasil, corrigidas para o viés de seleção amostral, revelam que as pessoas que anteciparam sua entrada no mercado de trabalho, antes de completar 16 anos de idade, sofrem uma penalização em seu salário de aproximadamente $21,5 \%$ e que uma parcela significativa desse efeito (80\%) é explicada pelo baixo acúmulo de capital humano devido à inserção ocupacional prematura, já que o efeito do trabalho infantil via mediação da educação é estimado em 17,2\%, aproximadamente. Tal resultado pode ser explicado pelo fato de o trabalho infantil ser responsável pela redução do desempenho educacional (Kassouf et al., 2016; Emerson et al., 2014) e pelo aumento das taxas de abandono escolar (Salata, 2019), que, por sua vez, podem se traduzir em baixos níveis de escolarização e, consequentemente, em menores oportunidades de ganhos no futuro. 


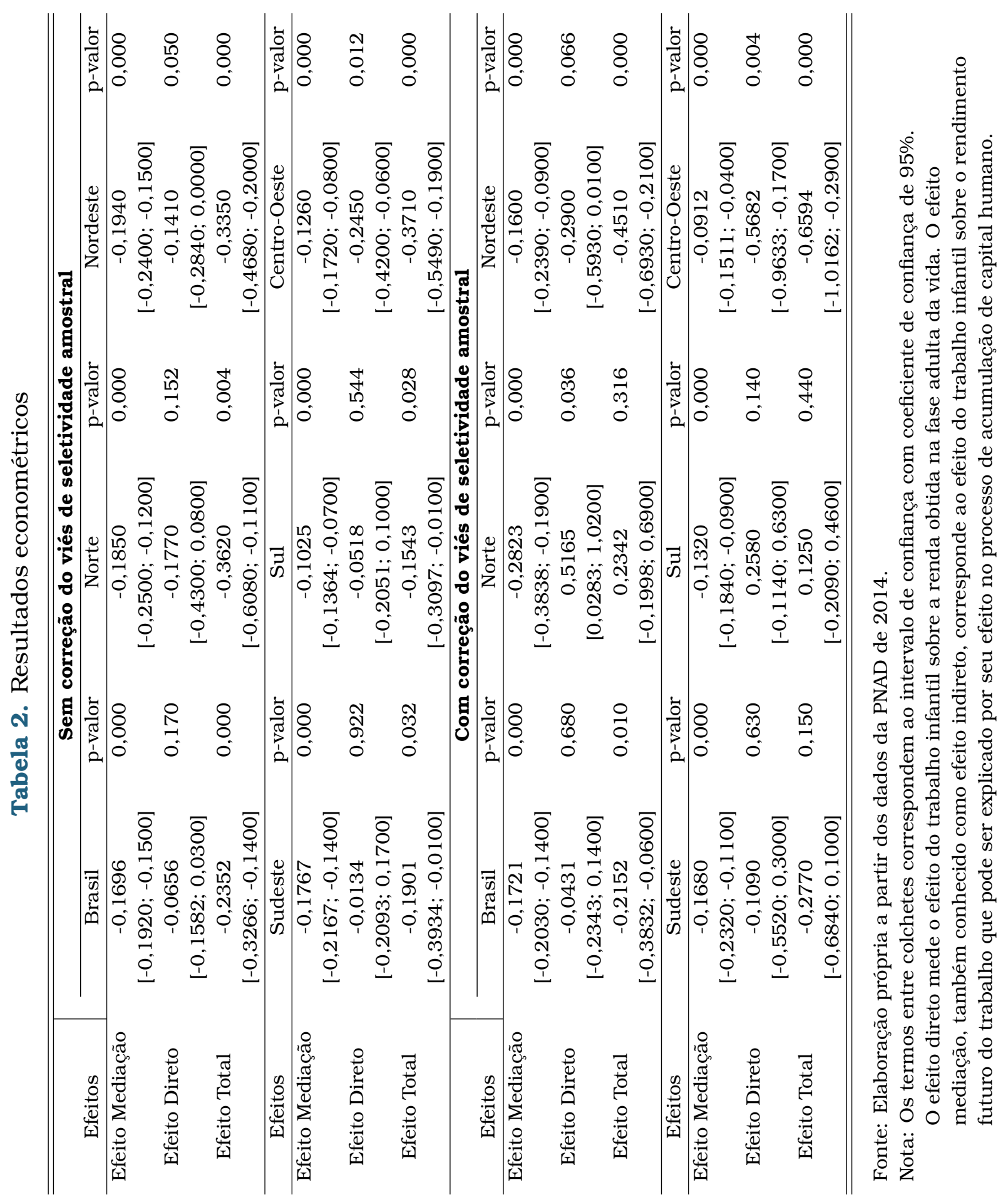


Nota-se, portanto, que as perdas salariais sofridas pelos trabalhadores brasileiros que ingressaram mais cedo no mercado ocupacional, antes da idade mínima para o trabalho, não se devem exclusivamente ao fato de eles terem trabalhado na infância, mas são explicadas, principalmente, pelo prejuízo educacional sofrido devido à inserção ocupacional prematura, o qual é responsável por pouco mais de três quartos do efeito total estimado. Portanto, os estudos que não levaram em consideração esse efeito indireto, via educação, irão superestimar de forma significativa o real efeito do trabalho infantil sobre o rendimento do trabalhador adulto.

Ao discriminar os dados por região geográfica, a fim de identificar possiveis disparidades regionais, as estimativas do efeito total do trabalho infantil apontam para a existência de maiores perdas de salário na fase adulta da vida no Centro-Oeste e no Nordeste do país, onde, em média, os indivíduos que anteciparam sua entrada no mercado de trabalho, antes dos 16 anos, ganham, respectivamente, 37\% e 33,5\% a menos que seus pares que ingressaram mais tarde. Quando corrigidas pela seletividade amostral, essas disparidades são ainda maiores, $66 \%$ e $45 \%$, respectivamente. Reduções elevadas no salário daqueles que ingressaram precocemente no mercado de trabalho também são verificadas para a região Norte. As estimativas sem correção do viés de seleção revelam uma redução total de 36,2\% no salário devido à inserção ocupacional prematura nessa região. No entanto, esses resultados se mostraram sensíveis à correção do problema de seleção não aleatória da amostra, em vista da perda de significância estatística do efeito estimado. O mesmo ocorre para o Sul e o Sudeste do país, embora as estimativas para essas regiões, antes de corrigir o viés de seleção, tenham revelado menores perdas.

Heterogeneidade no efeito do trabalho infantil sobre a capacidade de ganhos na idade adulta entre as grandes regiões do Brasil também tem sido evidenciada pela literatura (Kassouf e Santos, 2010; Monte, 2008). Os resultados de Monte (2008) revelam que os benefícios do retardamento da inserção do indivíduo no mercado de trabalho são maiores no Sudeste, no Centro-Oeste e no Nordeste, cujas estimativas indicam que adiar a entrada no mercado de trabalho em um ano aumenta o salário do indivíduo em 1,2\%. Kassouf e Santos (2010), ao analisarem as disparidades regionais e de gênero do efeito do trabalho infantil nos rendimentos na fase adulta no Brasil, também encontram evidências de que a inserção ocupacional precoce reduz de forma significativa o salário recebido quando adulto independente da região considerada. As estimativas para os homens apontam que adiar a entrada na força de trabalho em um ano aumenta o rendimento do trabalho em 4\%, 3,7\% e 3,1\% no Centro-Oeste, no Sudeste e no Nordeste, respectivamente. Para as mulheres, os maiores efeitos são encontrados para as regiões Nordeste $(6,2 \%)$, Sul $(6,2 \%)$ e Sudeste $(4,4 \%)$.

Em relação ao efeito indireto (mediação) da inserção prematura no mercado de trabalho, verifica-se que esse ganha força no Norte, no Sudeste e no Nordeste do país. Nessas regiões, a perda de renda devido ao efeito prejudicial do trabalho infantil sobre as oportunidades educacionais ao longo da vida é estimada em 28,2\%, 16,8\% 
e 16\%, respectivamente, após correção do viés de seleção amostral. Esse resultado pode ser justificado pelo fato de o trabalho infantil ser mais prejudicial à continuidade do investimento em educação nessas regiões do que nas demais (Monte, 2008; Mattos et al., 2006). Em uma pesquisa para o Brasil, Monte (2008) encontra evidências de que o efeito de adiar a entrada no mercado de trabalho em um ano sobre a quantidade de educação atingida na idade adulta é mais forte no Sudeste e Nordeste do país. Suas estimativas para essas regiões indicam que o retardamento da entrada no mercado de trabalho em um ano está associado a um aumento na escolaridade média de aproximadamente 0,27 anos.

No Centro-Oeste, por outro lado, o efeito mediação perde força, sendo responsável por apenas $13,8 \%$ do efeito total, visto que, ao contrário do que é verificado para as demais regiões, o efeito direto, não mediado pelo nível de escolaridade, é estatisticamente significante a menos de $5 \%$ de significância e explica mais de $80 \%$ do efeito total. O baixo diferencial de educação entre os trabalhadores que foram submetidos precocemente ao trabalho e os que não o foram nessa região, em relação às demais, conforme observado na análise descritiva dos dados, possivelmente explica esses resultados.

Diante do exposto, conclui-se que uma parcela significativa da penalização de renda sofrida por aqueles que ingressaram precocemente no mercado de trabalho é explicada pela baixa escolarização atingida quando adulto, devido aos efeitos prejudicais do trabalho infantil sobre a continuidade do investimento em educação. Logo, as consequências negativas do trabalho infantil sobre o processo de escolarização podem ser uma das principais barreiras à aquisição de melhores oportunidades de rendimento na idade adulta. Isso destaca a importância do combate ao trabalho infantil via educação para romper o ciclo de pobreza no país e, principalmente, nas regiões mais afetadas.

\subsection{Resultados da análise de sensibilidade}

A análise anterior sugere que o impacto da inserção ocupacional prematura no salário é potencializado por seu efeito no processo de escolarização do indivíduo. No entanto, esses resultados foram obtidos sob a hipótese de IS, de que não existe um fator de confusão comum não observado que afete tanto o nível educacional atingido quanto a aquisição de renda quando adulto. Essa suposição é necessária para a identificação dos efeitos obtidos na análise de mediação causal, mas não é garantido que ela seja atendida, mesmo em estudos experimentais (Keele et al., 2015; Imai et al., 2011 ). Nesta pesquisa, por exemplo, as habilidades cognitivas e não cognitivas préexistentes dos indivíduos, não observadas a partir dos dados utilizados neste estudo, poderiam motivar tanto a demanda por maiores níveis de escolaridade quanto a aquisição de melhores oportunidades de emprego na fase adulta da vida, o que poderia gerar uma correlação entre os termos de erro das equações de mediação e resultado, viesando as estimativas do ACME. Portanto, uma análise de sensibilidade é essencial 
para examinar a robustez dos achados empíricos a possíveis violações da hipótese de identificação chave.

Os resultados da análise de sensibilidade discutida na seção 3 são reportados na Tabela 3, em que são apresentados os valores do parâmetro $\rho$ para os quais o verdadeiro ACME é igual a zero. Vale lembrar que $\rho$ mede a correlação entre os termos de erro dos modelos de mediação e resultado e, portanto, representa o grau e a direção do fator de confusão não observado entre os níveis de escolarização e renda atingidos na idade adulta. Quando $\rho$ é igual a zero, a hipótese de IS é atendida e o verdadeiro efeito de mediação coincide com os que foram apresentados na Tabela 2. Caso contrário, a hipótese de identificação chave é violada. Esses resultados também são apresentados com mais detalhes nas Figuras A1 e A2, no apêndice, nas quais as estimativas do verdadeiro ACME são plotadas contra diferentes valores alternativos de $\rho$.

Tabela 3. Análise de sensibilidade

\begin{tabular}{|c|c|c|c|c|c|c|}
\hline \multirow[b]{2}{*}{ Parâmetros de sensibilidade } & \multicolumn{6}{|c|}{ Antes da correção do viés de seletividade amostral } \\
\hline & Brasil & Norte & Nordeste & Sudeste & Sul & Centro-Oeste \\
\hline$\rho$ em que $A C M E=0$ & 0,12 & 0,12 & 0,12 & 0,12 & 0,12 & 0,14 \\
\hline$R_{M}^{2^{*}} R_{Y}^{2^{*}}$ em que $A C M E=0$ & 0,0144 & 0,0144 & 0,0144 & 0,0144 & 0,0144 & 0,0196 \\
\hline$\tilde{R}_{M}^{2} \tilde{R}_{Y}^{2}$ em que $A C M E=0$ & 0,0092 & 0,0091 & 0,0088 & 0,0097 & 0,0104 & 0,0124 \\
\hline \multirow[b]{2}{*}{ Parâmetros de sensibilidade } & \multicolumn{6}{|c|}{ Após a correção do viés de seletividade amostral } \\
\hline & Brasil & Norte & Nordeste & Sudeste & Sul & Centro-Oeste \\
\hline$\rho$ em que $A C M E=0$ & 0,12 & 0,19 & 0,10 & 0,11 & 0,16 & 0,11 \\
\hline$R_{M}^{2^{*}} R_{Y}^{2^{*}}$ em que $A C M E=0$ & 0,0144 & 0,0361 & 0,0100 & 0,0121 & 0,0256 & 0,0121 \\
\hline$\tilde{R}_{M}^{2} \tilde{R}_{Y}^{2}$ em que $A C M E=0$ & 0,0092 & 0,0228 & 0,0061 & 0,0081 & 0,0184 & 0,0077 \\
\hline
\end{tabular}

Fonte: Elaboração própria a partir dos dados da PNAD 2014.

Nota: Efeito Médio de Mediação Causal (ACME). O parâmetro $\rho$ mede a correlação dos termos de erro das equações de mediação e resultado. $R_{M}^{2 *}$ e $R_{Y}^{2 *}$ representam, respectivamente, a proporção da variação não explicada no mediador e no resultado, que é explicada pelo fator de confusão não observado. Enquanto oscoeficientes de determinação $\widetilde{R}_{M}^{2}$ e $\widetilde{R}_{Y}^{2}$ correspondem, respectivamente, a proporção da variância original que é explicada pelo fator de confusão omitido nos modelos de mediação e resultado.

Verifica-se que as conclusões a respeito da direção do ACME para o Brasil, antes e após a correção do problema seleção amostral, são mantidas desde que $\rho$ seja menor que 0,12 , sugerindo que essas conclusões são perfeitamente robustas para a existência de um fator de confusão não observado que afete o mediador (nível educacional atingido) e o resultado (rendimento proveniente do trabalho obtido na idade adulta) em direções contrárias, pois, nesse caso, a estimativa do ACME é sempre negativa. Por outro lado, o resultado é menos robusto à violação da suposição de IS na presença de um fator de confusão capaz de afetar o mediador e a variável de resultado na mesma direção. No entanto, mesmo para essa situação alternativa, um valor negativo para ACME ainda é garantido se o produto das variações observadas nas variáveis de mediação $\left(\widetilde{R}_{M}^{2}\right)$ e resultado $\left(\widetilde{R}_{Y}^{2}\right)$, que são explicadas pelo fator de confusão não observado, 
for menor que 0,0092. Por exemplo, se as habilidades (não) cognitivas pré-existentes explicarem menos que $9,6 \%(\sqrt{0,0092})$ da variância no mediador e no resultado, as evidências de um ACME negativo relatado na análise original permanecem robustas.

O mesmo resultado é verificado para as estimativas das macrorregiões do país antes da correção do viés de seleção amostral. Todavia, após corrigir esse problema, os resultados obtidos para as regiões Nordeste, Sudeste e Centro-Oeste tornam-se mais sensiveis a violações hipotéticas da suposição de IS, necessária para a identificação do ACME. No Nordeste, o valor do parâmetro $\rho$ para o qual a estimativa pontual do ACME é igual a zero é 0,10, enquanto para as regiões Sudeste e Centro-Oeste esse valor é estimado em 0,11. Isso significa que um fator de confusão deve afetar o mediador e o resultado na mesma direção e explicar, respectivamente, mais que 7,8\%, 9\% e 8,8\% da variação total dessas variáveis nessas regiões para que o verdadeiro ACME mude de sinal. Assim, as estimativas encontradas para essas regiões são mais sensiveis à violação da suposição de IS que aquelas encontradas para o Brasil.

Por outro lado, a análise de sensibilidade aponta para uma maior robustez dos resultados encontrados para o Norte e o Sul do país. Nessas regiões, a direção da estimativa original do ACME sob a suposição de IS é mantida, diante da existência de um fator de confusão de pré-tratamento que afete a educação e a renda do indivíduo na idade adulta na mesma direção, a menos que o valor do parâmetro de sensibilidade $\rho$ seja maior que 0,19 e 0,16, respectivamente. Em outras palavras, os resultados originais desta pesquisa de um ACME negativo para as regiões Norte e Sul ainda são garantidos desde que esse fator de confusão não observado explique, respectivamente, menos que $15 \%$ e 13,6\% da variação no mediador (educação atingida quando adulto) e no resultado (rendimentos do trabalho na fase adulta da vida).

Em suma, esses resultados revelam que as evidências de um efeito mediação negativo para o rendimento do trabalho na idade adulta, via educação, são robustas a desvios da suposição de IS para a existência de fatores de confusão que afetem o mediador e o resultado em direções contrárias. Porém, para o caso em que o fator de confusão hipotético afeta essas variáveis na mesma direção, uma menor robustez é verificada, visto que uma violação moderada da suposição de IS poderia mudar a direção do ACME estimado.

\section{Conclusões}

Este estudo buscou estimar as disparidades regionais do efeito indireto do trabalho infantil, via mediação da educação, sobre os rendimentos na fase adulta da vida, no Brasil. Para esse propósito, utilizou-se como estratégia empírica a Análise de Mediação Causal, dentro da estrutura contrafactual, proposta por Imai et al. (2010a), aplicada aos dados da PNAD de 2014. Diferentemente dos métodos tradicionais de estimativas de impacto, frequentemente utilizados na literatura, essa metodologia permite decompor o efeito da entrada precoce no mercado de trabalho em duas parcelas: 
efeitos direto e indireto (mediação). Assim, esta pesquisa contribui para a literatura ao estimar as direções do efeito do trabalho infantil sobre o salário obtido na idade adulta e ao capturar a parcela desse efeito que é explicada pelo impacto prejudicial do trabalho infantil sobre a continuidade dos investimentos em educação.

Os resultados desta pesquisa revelam que parte significativa do efeito do trabalho infantil sobre a capacidade de geração de renda dar-se-á de forma indireta, via mediação do nível de escolaridade. Os trabalhadores brasileiros que anteciparam sua entrada no mercado de trabalho, antes dos 16 anos de idade, ganham em média $21,5 \%$ a menos que seus pares que ingressaram mais tarde, uma parcela significativa desse efeito (80\%) é explicada pelo baixo acúmulo de capital humano devido à inserção ocupacional prematura, sugerindo, portanto, que o efeito do trabalho infantil sobre a aquisição de renda quando adulto é potencializado pelos danos causados à continuidade do investimento em capital humano.

Ao estratificar a análise por região, constatou-se que as maiores penalizações salariais estimadas são verificadas no Centro-Oeste (66\%) e no Nordeste (45\%) do país. Além disso, verificou-se que o efeito mediação causal ganha força nas regiões Norte, Sudeste e Nordeste, onde as perdas de rendimentos devido ao efeito prejudicial do trabalho infantil sobre as oportunidades educacionais chegam a 28,2\%, 16,8\% e 16\%, respectivamente.

Diante do exposto, conclui-se que os estudos que não levaram em consideração o efeito indireto do trabalho infantil sobre o rendimento futuro do trabalho irão superestimar significativamente o seu real efeito. Assim, as perdas salariais sofridas por aqueles que anteciparam sua entrada no mercado de trabalho não ocorrem exclusivamente pelo simples fato de terem trabalhado enquanto criança, mas, principalmente, pelo prejuízo educacional sofrido devido à entrada precoce no mercado de trabalho. Portanto, este estudo contribui para a literatura que versa sobre o tema ao considerar um método que permite mensurar de forma mais precisa as consequências da inserção prematura no mercado ocupacional sobre as possibilidades futuras de rendimentos, pois, se apenas o efeito direto fosse levado em consideração, como nas diferentes análises tradicionais, o verdadeiro efeito do trabalho infantil seria superestimado.

\section{Referências}

Alam, I., Amin, S., e Rives, J. (2010). Determinants of child labor in the export and non-export sectors of Bangladesh. Journal of Economic Insight, 36(2):57-74.

Aransiola, T. J. e Justus, M. (2018). Child labor hazard on mental health: Evidence from Brazil. Journal of Mental Health Policy Economic, 21(2):49-58.

Basu, K. (1999). Child labor: cause, consequence, and cure, with remarks on international labor standards. Journal of Economic Literature, 37(3): 1083-1119. 
Basu, K. e Tzannatos, Z. (2003). The global child labor problem: What do we know and what can we do? The World Bank Economic Review, 17(2):147-173.

Beegle, K., Dehejia, R., e Gatti, R. (2009). Why should we care about child labor? the education, labor market, and health consequences of child labor. Journal of Human Resources, 44(4):871-889.

Bellani, L. e Bia, M. (2019). The long-run effect of childhood poverty and the mediating role of education. Journal of the Royal Statistical Society: Series A (Statistics in Society), 182(1):37-68.

Bezerra, M. E. G., Kassouf, A. L., e Arends-Kuenning, M. (2009). The impact of child labor and school quality on academic achievement in Brazil. IZA Discussion Papers, n. 4062. Institute for the Study of Labor (IZA).

Burrone, S. e Giannelli, G. (2019). Does Child Labor Lead to Vulnerable Employment in Adulthood? Evidence for Tanzania. Working Paper SSRN, n. 3390149.

Carrets, F. D., de Oliveira, J., Barbosa, M. N., e Menezes, G. (2015). Condicionantes do trabalho das crianças e adolescentes: uma análise para o Rio Grande do Sul. Revista Economia Politica do Desenvolvimento, 6(21):15-33.

Duarte, G. B. e Neto, R. d. M. S. (2014). Trabalho infantil e a renda na vida adulta: uma análise para o meio rural brasileiro. Revista Econômica do Nordeste, 45(1):7889.

Emerson, P. M., Ponczek, V., e Portela Souza, A. (2014). Child labor and learning.

Emerson, P. M. e Souza, A. P. (2008). Birth order, child labor, and school attendance in Brazil. World Development, 36(9):1647-1664.

Emerson, P. M. e Souza, A. P. (2011). Is child labor harmful? the impact of working earlier in life on adult earnings. Economic Development and Cultural Change, 59(2):345-385.

Fekadu, D., Alem, A., e Hägglöf, B. (2006). The prevalence of mental health problems in Ethiopian child laborers. Journal of Child Psychology and Psychiatry, 47(9):954959.

Freitas, C. O., Silva, F. A., e de Lima, J. E. (2017). Impacto do trabalho infantil no rendimento do indivíduo adulto no mercado de trabalho formal brasileiro. Acta Scientiarum. Human and Social Sciences, 39(3):281-291.

Heckman, J. J. (1979). Sample selection bias as a specification error. Econometrica, 47(1):153-161.

Houshmand, M., Seidel, M.-D. L., e Ma, D. G. (2014). Beneficial “child labor”: The impact of adolescent work on future professional outcomes. Adolescent Experiences and Adult Work Outcomes: Connections and Causes, 25:191-220. 
Imai, K., Keele, L., e Tingley, D. (2010a). A general approach to causal mediation analysis. Psychological Methods, 15(4):309-334.

Imai, K., Keele, L., Tingley, D., e Yamamoto, T. (2011). Unpacking the black box of causality: Learning about causal mechanisms from experimental and observational studies. American Political Science Review, 22(1):765-789.

Imai, K., Keele, L., e Yamamoto, T. (2010b). Identification, inference and sensitivity analysis for causal mediation effects. Statistical Science, 17(5):51-71.

Junior, N., Brito, H. M. R., e Silva, E. K. (2013). Transmissão intergeracional de educação e mobilidade de renda no brasil. Revista Economia e Desenvolvimento, 12(2):11-23.

Kassouf, A. L. (2007). O que conhecemos sobre o trabalho infantil? Nova Economia, 17(2):323-350.

Kassouf, A. L. (2015). Evolução do trabalho infantil no brasil. Sinais Sociais, 9(27):945.

Kassouf, A. L. e Hoffmann, R. (2006). Work-related injuries involving children and adolescents: Application of a recursive bivariate probit model. Brazilian Review of Econometrics, 26(1):105-126.

Kassouf, A. L. e Santos, M. (2010). Consequência do trabalho infantil no rendimento futuro do trabalho dos brasileiros: diferenças regionais e de gênero. 380. Encontro Nacional de Economia ANPEC.

Kassouf, A. L., Tiberti, L., Garcia, M., e Ono, I. (2016). Evidence of the impact of children's domestic and market labor on learning from school census data in Brazil.

Keele, L., Tingley, D., e Yamamoto, T. (2015). Identifying mechanisms behind policy interventions via causal mediation analysis. Journal of Policy Analysis and Management, 34(4):937-963.

Lambon-Quayefio, M. P. e Owoo, N. S. (2018). Child labour, future earnings and occupation choice: evidence from Ghana. International Journal of Social Economics, 45(12):1590-1608.

Mattos, L. B., Silva Muller, C. A., Lima, J. E., e Lírio, V. S. (2006). Efeitos do trabalho infantil sobre a educação na Região Nordeste do Brasil. Revista Econômica do Nordeste, 37(3):356-367.

Monte, P. A. (2008). Exploração do trabalho infantil no Brasil: consequências e reflexões. Economia, 9(3):625-650.

Moreira, G. C., Teixeira, E. C., Gomes, M. F. M., e Moreira, R. B. (2014). Determinantes do trabalho infantil na região Nordeste do Brasil, no ano de 2009. Revista Economia e Desenvolvimento, 13(2):258-272. 
Mussa, E., Admassie, A., e Mirzabaev, A. (2017). The effects of childhood work on early human capital formation and adult earnings in rural Ethiopia. Working Paper, n. 181. Universitäts-und Landesbibliothek Bonn.

Mussa, E. C. (2018). Long-term effects of childhood work on human capital formation, migration decisions, and earnings in rural Ethiopia. Working Paper, n. 114. Universitäts-und Landesbibliothek Bonn.

Mussa, E. C., Mirzabaev, A., Admassie, A., Nshakira-Rukundo, E., e von Braun, J. (2019). Does childhood work impede long-term human capital accumulation? Empirical evidence from rural Ethiopia. International Journal of Educational Development, 66:234-246.

Nishijima, M., Souza, A. P. F. d., e Sarti, F. M. (2015). Trends in child labor and the impact on health in adulthood in Brazil from 1998 to 2008. Cadernos de Saúde Pública, 31:1071-1083.

O’Donnell, O., Rosati, F. C., e Van Doorslaer, E. (2005). Health effects of child work: Evidence from rural vietnam. Journal of Population Economics, 18(3):437-467.

Paiva, J. S. d. (2013). Trabalho infantil no Brasil: determinantes da redução entre 2003 e 2011 e efeitos sobre a escolaridade e o rendimento na vida adulta. Dissertação de Mestrado, Escola de Economia de São Paulo da Fundação Getúlio Vargas.

Ramalho, H. M. d. B. e Mesquita, S. P. d. (2013). Determinantes do trabalho infantil no Brasil urbano: uma análise por dados em painel 2001-2009. Economia Aplicada, 17(2):193-225.

Reis, M. C. e Ramos, L. (2011). Escolaridade dos pais, desempenho no mercado de trabalho e desigualdade de rendimentos. Revista Brasileira de Economia, 65(2):177205.

Salata, A. (2019). Razões da evasão: abandono escolar entre jovens no Brasil. Interseções - Revista de Estudos Interdisciplinares, 21(21-1).

Silva Ciríaco, J., dos Anjos Júnior, O. R., e Lombardi Filho, S. C. (2019). Uma análise do trabalho infantil na região sul do Brasil. Brazilian Journal of Development, 5(8):13500-13514.

Souza, E. L. d. C. e Pontili, R. M. (2008). Trabalho infantil e sua influência sobre a renda e a escolaridade da população trabalhadora do Paraná. Anais do Encontro de Economia da Regiao Sul.

(G) Este artigo está licenciado com uma CC BY 4.0 license. 


\section{Apêndice}

Figura A1. Análise de sensibilidade dos resultados antes da correção do viés de seleção

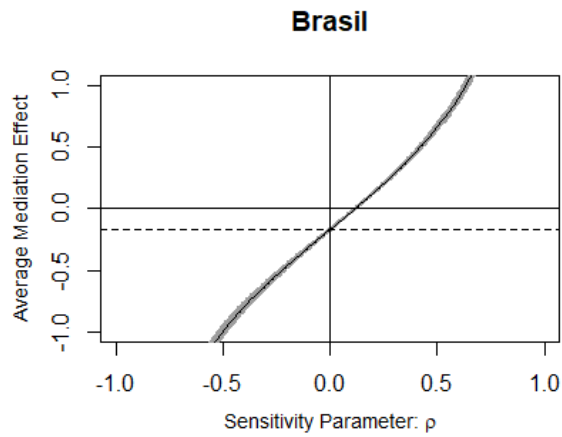

Nordeste

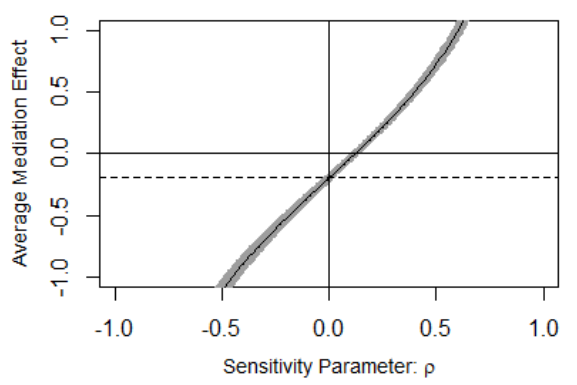

Sul

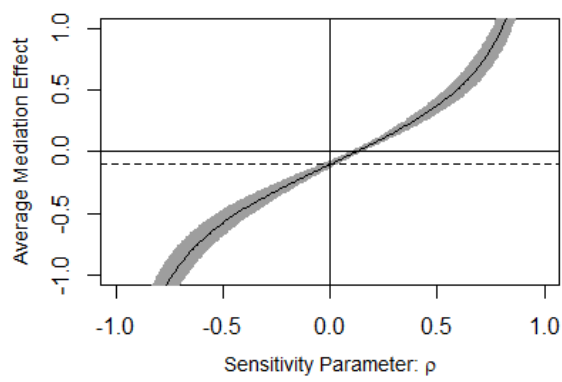

Norte

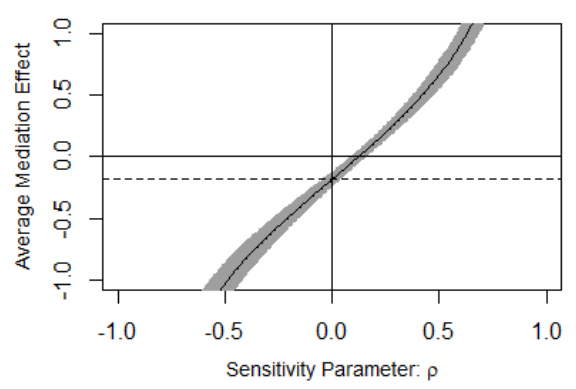

Sudeste

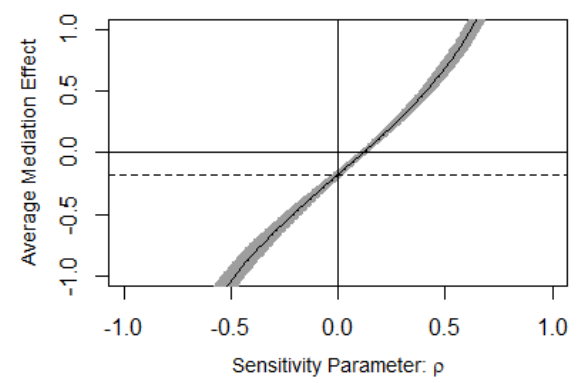

Centro-Oeste

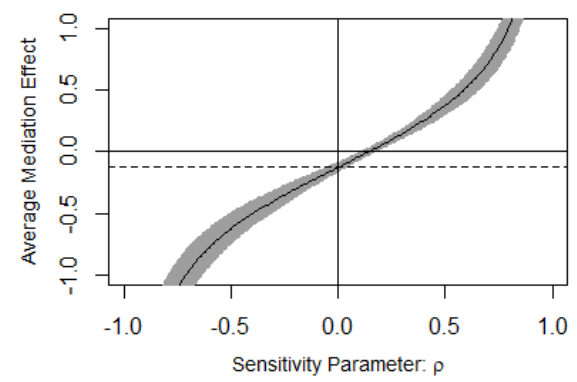

Fonte: Elaboração própria a partir dos dados da PNAD de 2014. 
Figura A2. Análise de sensibilidade dos resultados após correção do viés de seleção

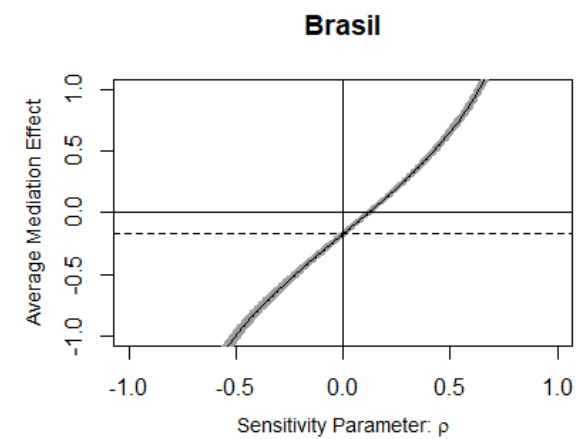

Nordeste

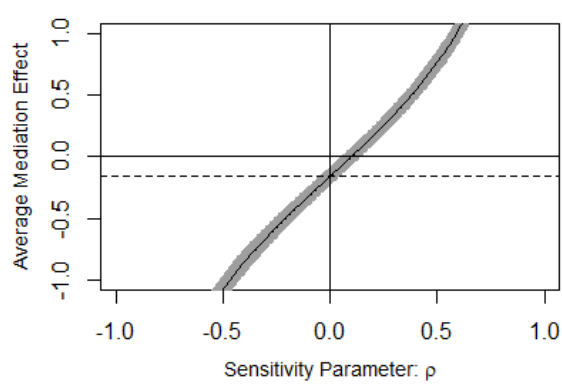

Sul

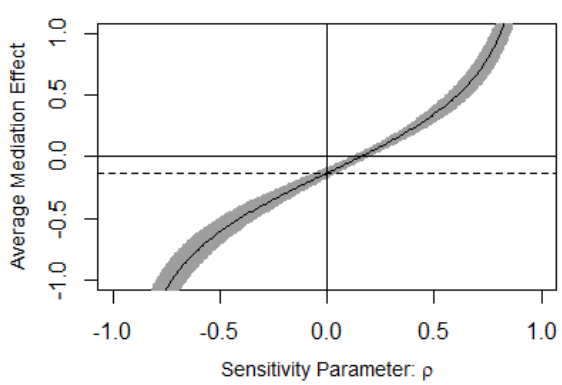

Norte

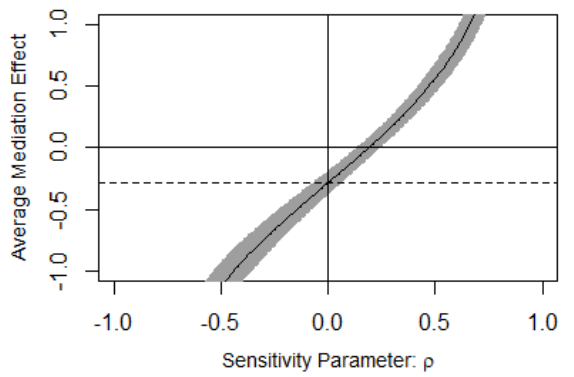

Sudeste

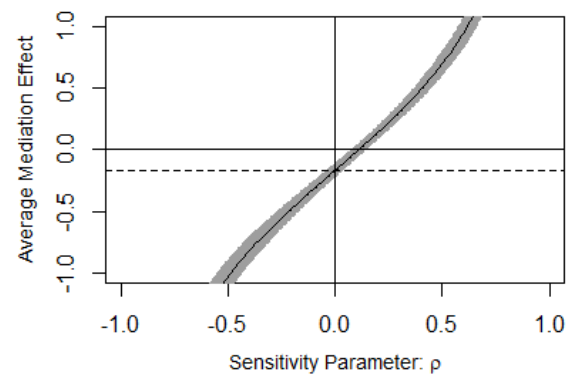

Centro-Oeste

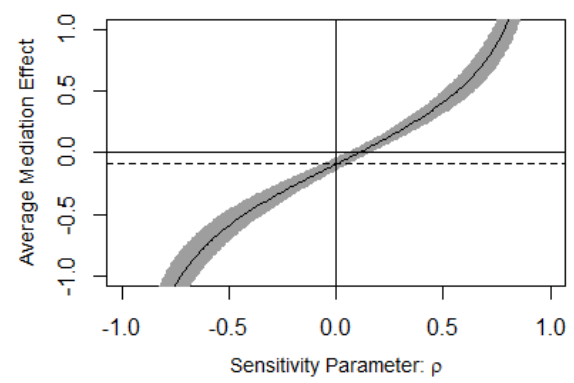

Fonte: Elaboração própria a partir dos dados da PNAD de 2014. 